\title{
Sujeito e demiurgia no gesto fotográfico
} Ana Taís Martins Portanova Barros

\section{Resumo}

A partir de enunciados que dão pistas a propósito da criatividade e da subjetividade na produção teórica brasileira sobre fotografia, discute-se a noção de sujeito que aí se apresenta, confrontando-a com aquela derivada das teorias contemporâneas que sustentam 0 estilhaçamento da identidade. A conclusão de que o subjetivismo nega a criatividade por causa de seu binarismo leva-nos a buscar, junto a Heidegger e a Wunenburger, conceitos que possam viabilizar 0 equacionamento da ideia de um sujeito instável com a da criação. Reconhece-se um obstáculo antropológico - e não epistemológico - oferecido pela constante que redunda ora no pensamento esquizomorfo ora no pensamento gliscomórfico, consubstanciado simultaneamente na afirmação da soberania arrogante sobre e na integração alienada à (imagem) técnica. Conclui-se pela necessidade de uma saída bifurcada através da coincidentia oppositorum que faz de um terceiro elemento o ponto de sustentação e justificação do que inicialmente foi um binarismo, restituindo a demiurgia possível ao sujeito multiplicável.

\section{Palavras-chave:}

Fotografia. Sujeito. Criatividade.

Ana Taís Martins Portanova Barros | anataismartins@ hotmail.com

Doutora em Ciências da Comunicação pela Universidade de São Paulo - USP. Professora do Programa de Pós-Graduação em Comunicação e Informação e da Graduação em Comunicação Social da Faculdade de Biblioteconomia e Comunicação da Universidade Federal do Rio Grande do Sul - FABICO/UFRGS.

\section{Introdução}

"Façamos o homem à nossa imagem, conforme nossa semelhança" (Gênesis:1,26, 1983, p. 24).

0 Criador concede à criatura dons afiliados aos Seus próprios, de modo que a criatura seja, ela também, criadora. Não obstante a tranquilizadora informação do Gênesis, a pergunta sobre as possibilidades criativas da humanidade é recorrente. Quando se tratam de atos intermediados por fortes aparatos técnicos, como no caso da fotografia, a insegurança quanto à marca humana no produto final cresce e insta a reflexão sobre quem é, afinal, o sujeito desse predicado.

A noção de sujeito parece fazer par imediato com a de objeto (objectum), a primeira se referindo ao que está posto dentro $(s u b)$ e a segunda ao que está posto diante $(o b)$ do homem. Ao recensear algumas noções de sujeito, Hall (1999, p. 3545) distingue três principais: a do Iluminismo, a da Sociologia e a da Pós-Modernidade. Ele aponta as características de cada uma, sendo que nas duas primeiras o sujeito tem um núcleo relativamente estável, algo como uma essência 
interior, e na terceira esse núcleo se esfacela, sendo a identidade algo cambiante, multiplicada e multiplicável. Na passagem do sujeito moderno ao sujeito pós-moderno, segundo Hall (1999), poderiam ser destacados cinco momentos que sinalizaram o descentramento total deste sujeito: a rejeição, por Marx, do homem como essência de sua base teórica; a teoria freudiana de que 0 homem é definido por processos inconscientes; a teoria de Saussure de que o homem não é autor do que diz, pois a língua que ele usa para se expressar lhe é preexistente; a teoria de Foucault de que o indivíduo é vigiado pelo poder coletivo; 0 feminismo, que teria trazido a família e as coisas domésticas para o seio da contestação social.

Perderá o sujeito sua voz ativa ao perder seu núcleo identitário? Não sendo possível lhe atribuir uma marca distintiva, capaz de diferenciá-lo sempre e em meio a qualquer número de outras marcas, terá ainda esse sujeito o dom demiúrgico que lhe foi concedido no momento da sua criação? Quem é este homem que já não tem mais certeza do lugar que ocupa no mundo? 0 que pode ele?

Os abalos na autoimagem do homem parecem ser recorrentes na civilização ocidental. A Revolução Copernicana, ao tirar o homem do centro do universo, fê-lo perceber que desconhecia a sua posição relativa no mundo; Freud nos informou que o homem não sabia nem mesmo o que se passava dentro de sua própria cabeça e, quase ao mesmo tempo, a Física demonstrou que as certezas sobre o mundo material são extremamente instáveis. Esse homem desconhecedor de si mesmo acreditará ainda na sua própria autonomia criativa?

Sobre este ponto se fará uma reflexão a partir dos resultados parciais de pesquisa que ora desenvolvemos e que tem como objetivo geral recensear as relações entre ciência, imaginário e senso comum presentes na produção acadêmica brasileira sobre fotografia.

\section{Uma pergunta}

Este artigo se constrói, especificamente, com base em uma pergunta sobre a criatividade na fotografia que o protocolo de análise faz aos textos que constituem o corpo empírico: ela existe? Se sim, de onde vem? As respostas encontradas permitiram concluir que a fotografia, malgrado ser uma expressão atravessada por toda ordem de contradições, ainda é vista como realizada por um sujeito moderno, portador de uma identidade estável. Procuramos, aqui, equacionar algumas consequências teóricas desse ideário, fazendo dialogar os textos do corpo empírico da pesquisa com autores externos a ele.

Foi mapeada a produção intelectual sobre fotografia no Brasil realizada num período de dez anos, de 1999 a 2009 (data do início da pesquisa). A partir do diretório de teses e dissertações da Coordenação de Aperfeiçoamento de Pessoal de Nível Superior (CAPES) e do diretório de grupos de pesquisa do Conselho Nacional de Desenvolvimento Científico e Tecnológico (CNPq), 
procuraram-se trabalhos que se debruçassem sobre a fotografia como episteme, fornecendo pistas para o que seria uma teoria da fotografia brasileira. Utilizando-se a palavra fotografia como expressão de busca, junto ao CNPq chegou-se ao número de 111 grupos de pesquisa; observandose a produção intelectual destes 111 grupos, foi necessário descartar 101 deles por utilizarem a fotografia apenas de modo marginal, para buscar informações visuais. Passou-se, então, ao mapeamento da produção intelectual dos 10 grupos de pesquisa restantes, publicada durante os 10 anos de abrangência da pesquisa, e chegouse a 29 trabalhos efetivamente focados sobre o que se poderia chamar de teoria ou mesmo filosofia da fotografia.

Junto à CAPES, 0 total geral foi de 65 teses $\mathrm{e}$ dissertações que responderam à pesquisa com a palavra fotografia na expressão de busca. Após análise de seus resumos, chegou-se ao número de 16 trabalhos adequados aos critérios de formação do corpo empírico da pesquisa.

No estágio atual da pesquisa, procede-se ao recenseamento dos princípios heurísticos explícitos ou subentendidos nos textos. A questão da criatividade, sendo estratégica na discussão sobre os fundamentos epistemológicos da imagem técnica, é especialmente examinada. Tendo sido analisado 45\% do corpo empírico, observa-se que $36 \%$ dos trabalhos não tocam na questão da criatividade em fotografia, detendo-se sobre o que denominam como signo fotográfico. ${ }^{1} 0 \mathrm{~s}$ $64 \%$ dos trabalhos restantes veem a criatividade na fotografia como apoiada na subjetividade do fotógrafo, concebida a partir de uma individualidade, de um olhar pessoal, como no seguinte trecho:

\section{Cada fotógrafo lança um olhar sobre as coisas do mundo como método cognitivo, uma ma- neira própria de pensamento, no qual a técnica está a serviço da interpretação. Singulariza a leitura ao completá-la com seu próprio sentido, retira as coisas do mundo, codifica-as em seu interior em conformidade com tudo que 0 constitui como ser único e as devolve de onde as tirou, multiplicando nela mesma os seus significados (GATTO, 2004, p. 102).}

No trecho, é de se notar as posições respectivas do fotógrafo de um lado e do mundo do outro; o fotógrafo na posição de sujeito e o mundo na posição de objeto a ser conhecido. A fotografia tem aí o papel de instrumento de cognição e 0 fotógrafo é um sujeito que possui uma essência, "tudo o que o constitui como ser único". 0 núcleo identitário permanece estável no processo de conhecer o mundo e o mundo corre 0 risco de também permanecer estável no final, pois a ele são devolvidas, do mesmo lugar que saíram, as coisas dele retiradas pelo fotógrafo. Há o aceno com a multiplicação de significados, mas pode-se perguntar se essa multiplicação não é aquela que 0 desdobramento do Mesmo em pares faz, já que os dois polos da relação continuam nos seus lugares. 
Então, embora a ideia do estilhaçamento do sujeito pareça ter já alcançado um nível de difusão considerável, ela é traída en petit, quando suas possíveis consequências são colocadas sob lente de aumento, mostrando que não se abandonam, assim, de afogadilho, hábitos de pensamento cultivados durante milênios e apenas eventualmente colocados em causa.

A fotografia como reprodução do real, ou seja, como objetividade, como acesso direto ao mundo, parece estar suficientemente assumida, já que os trabalhos quase sempre remetem a responsabilidade da produção fotográfica a um sujeito que olha as coisas de modo peculiar. No entanto, mesmo ao repelir a ideia da fotografia como uma janela para o mundo, há uma tendência a se pensar a fotografia como uma janela para o mundo de alguém (o fotógrafo), como no seguinte trecho:

0 que é, para nós, representação 'natural' é, na verdade, uma forma de apreensão da 'realidade' (em função de uma codificação da perspectiva renascentista), ou, em outros termos, poder-se-ia dizer que a fotografia significa o que alguém, autorizado, viu, antes de nós, e este mesmo alguém, o fotógrafo, dá-nos a sua forma de ver (CHAMARELLI FILHO, 2002, p. 204, grifos do autor).

A noção de sujeito uno se calca, do ponto de vista lógico, nos primórdios da sistematização do pensamento racional, quando Sócrates desafiou a mostração polissêmica, ambígua e contraditória, característica do pensamento mítico, com a demonstração racional da existência de apenas duas possibilidades de pensamento: 0 certo e 0 errado. Platão refinou as ideias do mestre apresentando sua famosa alegoria da caverna que, como pontua Heidegger (1989 apud MARCONDES, 1997, p. 267), inaugura a ideia de que 0 sujeito tem de adequar seu olhar ao objeto: 0 homem que sai da caverna (das trevas da ignorância) precisa adaptar seus olhos para não ser ofuscado pela luz (visão da verdade). Nasce aí, segundo Heidegger, a concepção de conhecimento baseado numa relação sujeito-objeto, que entende a identidade como um traço do ser. No entanto, o filósofo está convicto de que a verdade é outra:

0 homem é manifestamente um ente. Como tal, faz parte da totalidade do ser, como a pedra, a árvore e a águia. Pertencer significa aqui ainda: inserido no ser. Mas o elemento distintivo do homem consiste no fato de que ele, enquanto ser pensante, aberto para o ser, está posto em face dele, permanece relacionado com 0 ser e assim the corresponde. 0 homem é propriamente esta relação de correspondência, e é somente isto. 'Somente' não significa limitação, mas uma plenitude (HEIDEGGER, 2006, p. 44).

Essa relação de correspondência de que fala 0 autor e que constitui o homem não se assimila à relação sujeito-objeto. A correspondência do ser com 0 ente é um terceiro, um ponto de apoio - e não simplista intermediário - entre os distintos. Retomaremos isso adiante.

0 sujeito, o que está dentro (sub-jectum), se distingue do que está fora (ob-jectum). 0 subjetivismo (tanto quanto o objetivismo) expulsa 0 terceiro elemento, coerente que 
é com o princípio da identidade (A é A),

da não contradição (impossibilidade de, simultaneamente, ser A e não A) e do terceiro excluído (A ou não-A). A criatividade na fotografia como resultante do olhar pessoal do fotógrafo sobre o mundo é tributária, simultaneamente, da dualidade sujeito-objeto, do determinismo e da desconfiança em relação às aparências. 0 fotógrafo que olha o mundo é sujeito que se separa do objeto, objeto este que é em si, esperando apenas ser descoberto sob as enganadoras aparências que impedem o olhar distraído de vê-lo. Numa relação sujeito-objeto não há criação, e sim dois polos disjuntados e estáveis, de modo que creditar à subjetividade a manifestação criativa na fotografia é destituir 0 homem dessa faculdade criativa.

0 aparato técnico da fotografia carrega na sua gênese as marcas da binaridade, refletindo e reforçando o ideário positivista de sua arché. A fotografia chegou num momento em que, muito embora os desenvolvimentos da ciência já indicassem grandes dificuldades de se prever o comportamento da natureza, parecia ao homem possível dominar o mundo. 0 fato de a fotografia ser executada através de uma máquina, interposição necessária entre o fotógrafo e 0 mundo fotografado, certamente é motor, em cada ato fotográfico, da separação sujeito-objeto. Separação tanto mais trágica para a criatividade quanto mais é acentuada pela intermediação técnica, onde não é 0 fotógrafo 0 sujeito da passiva coisa fotografada, e sim a própria máquina, autorizando Flusser (2002, p. 54) a concluir que 0 homem só fotografa o fotografável: "Quem contemplar 0 álbum de um fotógrafo amador, estará vendo a memória de um aparelho, não a de um homem".

Uma reação possível é, sim, render-se à fotografia como "[...] um instrumento por excelência para a apreensão e transmissão do conhecimento, pois objetiviza o mundo em seu processo" (MARTINI, 1999, p. 40), como afirma um dos textos examinados na pesquisa. Mas se "a habilidade do fotógrafo estaria em responder impecavelmente à programação, e mesmo superá-la com cuidado, através da qualidade de suas fotos e da acuidade de seu olhar" não seria esse fotógrafo ainda submisso ao aparelho, já que tem de sempre provar que lhe é superior? (MARTINI, 1999, p. 43) Mais uma vez, é a criatividade fundada na individualidade que acena com a promessa do salto sobre 0 abismo, desafiando até mesmo a consistência do referente:

Através desse olhar, criativo, que elabora um
trabalho no signo fotográfico, a documenta-
ção, por diversas vezes, assume uma poética,
apesar da dominância do referente. E essa
informação semântica altamente estetizada
dá um caráter artístico para a fotografia, que a
leva a se tornar uma obra autoral, afastando-se
então, da condição única de registro (MORAES,
1999, p. 116).

Referente, Outro, mundo: lá está ele à espreita, cortando os laços com o sujeito, ameaçando-0, humilhando-0. De nada adianta sustentar que "a interação com o mundo exterior possibilita 
criar, interpretar e significar as experiências indefinidamente" (GATT0, 2004, p. 107) se esse mundo exterior, afinal, está dado. No subjetivismo, paralelo ao objetivismo, não há criação, e sim reprodução. A separação sujeito-objeto não condiz com a epifania demiúrgica do ato de fotografar.

\section{A relação}

Tributar a criatividade na fotografia à

subjetividade parece ser um ato desesperado em defesa da liberdade do homem frente à máquina que, mesmo sem vida, anima-se de ameaças ao seu criador, como pontua este trecho analisado:

Mesmo sendo o inventor do aparelho, alguma coisa Ihe escapa. 0 homem constrói 0 aparelho, e este, manipulado por ele, produz a imagem e, no entanto, esta, ao ser produzida, foge da criação exclusivamente humana, que se submete a uma parceria com 0 aparelho (MARTINI, 1999, p. 40).

0 embate toma corpo; outro trecho da análise encaminha a solução através da busca de

[...] um precário equilíbrio entre os dois componentes do sujeito: um, relativo aos automatismos que não cessam de ganhar autonomia em relação aos que os programaram ou deles farão uso; outro, pela tentativa de resistência a essa dependência tecnológica, através da redefinição da própria identidade frente às mudanças tecnicistas (COSTA, 2008, p. 16).

A oscilação entre estes dois extremos é verificável em duas tendências contemporâneas: a exacerbação do uso das técnicas, produzindose fotografias que constituem um verdadeiro mostruário dos recursos dos programas de edição de imagem, e o retorno aos processos fotográficos primitivos, que dispensam mirabolâncias digitais. Opostos em sua fenotipia, os dois comportamentos se irmanam na sua raiz arquetípica: a angústia do caos gerada pela perda da supremacia. No conflito criador versus criatura, a ordem subvertida redunda no domínio daquele que estava na origem por aquele que foi originado. 0 sujeito é subjugado pelo objeto porque não renuncia ao que considera sua essência, qual seja, a capacidade de se manter o mesmo em meio à turbulência. Com a cabeça teimosamente erguida, quer dar prova de ser capaz de adentrar a caixa preta, exaurir seus recursos e reprogramá-la, mas tudo o que faz é inserir ali possibilidades que são desdobramentos das anteriores. A estratégia oposta não redunda em melhores resultados, quando o sujeito, que se crê 0 Mesmo, desdenha a tecnologia que ele próprio desenvolveu e se entrega à nostalgia da inocência dos primórdios, quando uma placa de metal recoberta com betume da Judéia era suficiente para produzir uma fotografia. A tragicidade disto está no homem, em vez de atrair 0 monstro para 0 terreno em que poderia vencêlo facilmente, adentrar o território inimigo e ali tombar refém.

Para escamotear essa derrota, podem-se alegar propriedades mediadoras do gesto fotográfico que servem de ponte entre o Mesmo e o Outro, como neste trecho de texto analisado: "[...] 0 fotógrafo atua como mediador cultural ao traduzir em imagens técnicas sua experiência subjetiva frente ao mundo social" (MAUAD, 2008, p. 37). 
Ou, ainda: "A operação fotográfica estabelece relações entre sujeito e tempo; entre sujeito e espaço; entre sujeitos, e entre sujeito e uma situação dada" (MARTINS-COSTA, 2006, p. 82). A superabundância de relações, no entanto, não chega à complexificação quando é simples somatória de um com um, formando pares que sempre retornam ao Mesmo.

Pode-se, também, recorrer à libertação do significado em vista da polissemia onipresente naquilo que, embora sendo simples figuração, convencionou-se chamar imagem:2 "A fotografia é uma convenção do olhar e uma linguagem de representação e expressão de um olhar sobre 0 mundo. Nesse sentido, as imagens são ambíguas [...] e passíveis de múltiplas interpretações [...]" (MONTEIRO, 2008, p. 174). Mas a proatividade do mediador e a pluralidade das leituras ainda supõem 0 sujeito em luta com uma exterioridade que lhe é adversa.

Algo com qualidade diferente se esboça no seguinte trecho em que a fotografia, depois de usada, é desprezada, abandonada, impiedosamente descartada, sem melindres de um sujeito que não admite ver a obra que julga sua, assim, posta de lado. É necessário que 0 gesto fotográfico transcenda a coisa fotográfica para ser gesto criativo, para produzir uma imagem simbólica que, tendo, se quisermos, em um sujeito o mote de seu nascimento, não repousa nele nem se justifica por ele; se uma vez foi expressão máxima da individualidade, essa imagem reverte 0 vetor do processo e reconduz o sujeito ao coletivo:

Essa combinação caracteriza a fotografia como uma alegoria na qual se justapõe a assinatura do autor e uma simbolização, a partir das quais se determina finalmente a sobrevivência da imagem contra a cegueira, isto é, a possibilidade da ocorrência do afeto que fecha 0 circuito entre os sujeitos e a imagem como fenômeno. A partir dessa articulação entre assinatura e convenção simbólica define-se a última modalidade da aparição da fotografia, que, em seu automatismo, possibilita uma aparição da foto como escória ou alucinatória da imagem, isto é, a produção de sentido que despreza o traço e ocorre em um desequilíbrio da articulação na qual, à despeito daquilo que está representado ou não, infere-se sentido (BARTHOLOMEU, 2008, p. 17).

Muito embora o traço fotográfico seja, enfim, desprezado, deixa-se supor que o é por um defeito de origem, 0 "seu automatismo" que faz dele "escória ou alucinatória da imagem". A indicação do alucinatório e do representado seduz 0 pensamento a procurar 0 verdadeiro, que estaria em algum outro lugar, abrindo caminho para reinstaurar a dualidade.

\section{0 processo}

As teorias contemporâneas (para não dizer pósmodernas) do sujeito falam de seu estilhaçamento porque, em vez da afirmação de uma identidade, o que vigora é "[...] uma cultura que nega a uniformidade de um indivíduo ou processo ao 
longo de todas as suas fases e circunstâncias

[...] e que navega nas águas de um eu fluído, multiforme e problemático" (COELHO, 2005, p.

154). É necessário, então, pensar em um novo sujeito - que certamente não fará mais jus a esse nome, um sujeito que, como lembra Flusser (2008, p. 104), não mais criará "na solidão da geleira, nos mais altos picos (Nietzsche)":

\section{Atualmente, a massa das informações dispo- níveis adquiriu dimensões astronômicas: não cabe mais em memórias individuais, por mais geniais que sejam. [...] a memória humana se revela lenta demais para processar semelhante quantidade de dados. 0 diálogo interno e solitá- rio se tornou inoperante. Exigem-se grupos de memórias individuais assistidos por memórias artificiais (laboratórios, comitês, grupos de pesquisa e de realização).}

E Flusser (2008, p. 107), que tomou a fotografia como paradigma dos automatismos de nossa sociedade tecnológica, conclui: " 0 jogo futuro fará a abstração 'eu' sob a forma do 'nós outros'”.

No entanto, a ideia de sujeito com a identidade tranquilamente estilhaçada, que se reconhece como amálgama de muitos outros, parece enfrentar um obstáculo não epistemológico, mas antropológico: aquilo que Durand (1997) chama de universo imaginário esquizomorfo. Nele, a idealização e o recuo autista são isótopos do par de arquétipos substantivos arma heróica-vínculos. ${ }^{3}$
Se quisermos pensar em um sujeito que não mais 0 moderno, não mais obrigado à coerência interna, não mais em luta com o objeto, teremos de enfrentar esta constante antropológica que nos leva continuamente $\mathrm{a}$, em resposta à solicitação por vínculos, erguermos a espada que ameaça e dilacera.

Renunciar à distinção não se resolve correndo para a indistinção, pois isso é, ainda, gesto do pensamento identitário. Como já foi dito acima, o um é para onde o par sempre volta; "o pensamento identitário tenta reduzir a diferenciação a uma alternativa entre a confusão e a separação de duas determinações que repartem entre si o campo do dado" (WUNENBURGER, 1990, p. 47).

Outro equacionamento possível seria o proposto por Heidegger (2006, p. 44), que retomamos agora: aberto para 0 ser, em face dele, 0 homem lhe corresponde, e "é propriamente esta relação de correspondência". 0s vários descentramentos e 0 despedaçamento do sujeito se tornam compreensíveis e suportáveis se a definição do homem carrega não a estabilidade induzida pela "lógica dilemática do homogêneo e do heterogêneo, da conjunção e da disjunção" (WUNENBURGER, 1990, p. 48), e sim a flexibilidade da correspondência que, feita de 
conexões, também abriga os interstícios que oferecem espaço, ensejo, ponto de gancho para novas correspondências. Então, aí, o homem, não mais sujeito purificado do objeto, não mais acidente do ser, é o termo terceiro que, bem distante do simples caminho do meio, se complexifica, abrindo-se para uma multiplicidade de ligações. Um terceiro que não se estabiliza em mediador, pois não se apoia lá e aqui, sendo antes 0 apoio do Mesmo e do Outro.

A distinção, assim, não desaparece em benefício de uma gliscomorfia; em vez de se passar do dualismo identitário para o monismo, antes se ingressa audaciosamente no seio da coincidentia oppositorum, onde o múltiplo nunca é o binário, mas ternário, como explica Wunenburger (1990, p. 68-69):

Só na tríade podem coexistir ao mesmo tempo ligações e repulsões, evoluindo segundo equilíbrios e desequilíbrios alternativos. [...] Só uma tríade, que torna possível uma relação e uma variação dos componentes, que traz consigo uma variedade de disposições, inaugura verdadeiramente 0 múltiplo.

A tríade, não se confundindo com uma tricotomia que isola o terceiro em relação aos dois primeiros, permite que a criatividade exploda no seio da repetição característica da máquina, não por causa de uma subjetividade arrogada superior, mais refinada, mais sensível do que é sentido como a grosseira técnica, mas pelo jogo entre o mundo, a técnica que aborda esse mundo e o produto da abordagem - a fotografia que multiplica 0 ser. 0 homem pode tanto ser objetivador da técnica quanto objetivado por ela, e esse jogo, que não é alternância, e sim simultaneidade, define o ser como humano. Sim, "0 fotógrafo não pode fotografar processos" (FLUSSER, 2002, p. 31), mas os processos podem ser colocados em movimento a partir do gesto fotográfico que será, então, a cada vez, outra fotografia. Não interessa mais se a fotografia possível é somente aquela inscrita previamente no aparelho ou se é resultante de uma subjetividade sobreposta ao mundo; não é mais necessário afrontar a imagem técnica, afirmar a superioridade do sujeito sobre o objeto. Esse sujeito recupera sua autonomia quando se posta perigosamente em face do objeto, reconhecendo-se nele, deixando-se mesmo objetivar por ele, ciente que está de não haver garantias de integridade, de que o seu "eu" continua a ser um "eu" mesmo na voz passiva porque sua voz ativa é que permitiu a entrega.

É aí que reside a ação criadora; é aí que o homem, não mais sujeito esterilizado na sua introjeção, não mais tomando distância do Ser, pode novamente conjugar o verbo, e, se quisermos, do verbo fazer carne: reinstala-se a demiurgia. Não mais a demiurgia do sujeito solitário em seu laboratório de genialidade, redentora de uma humanidade aprisionada pelos automatismos da técnica, mas, ainda, uma demiurgia.

\section{Referências}

BARTHOLOMEU, Cezar Tadeu. Incompletude, fotografia. 2008. $299 \mathrm{f}$. Tese (Doutorado em 
Linguagens Visuais.) - Escola de Belas Artes, Universidade Federal do Rio de Janeiro, Rio de Janeiro, 2008.

\section{CHAMARELI FILHO, Milton. A filosofia da}

fotografia. 2002. $251 \mathrm{f}$. Tese (Doutorado em

Comunicação e Semiótica) - Pontifícia Universidade

Católica de São Paulo, São Paulo, 2002.

COELHO, Teixeira. Moderno pós moderno: modos

\& versões. São Paulo: Iluminuras, 2005.

COSTA, Ana Angélica Teixeira Ferreira da.

Imagens precárias. 2008. 143 f. Dissertação

(Mestrado em Arte e Cultura Contemporânea) -

Instituto de Artes, Universidade do Estado do Rio

de Janeiro, Rio de Janeiro, 2008.

DURAND, Gilbert. A imaginação simbólica.

Lisboa : Edições 70, 2000.

\section{. As estruturas antropológicas do}

imaginário: introdução à arquetipologia geral.

São Paulo: Martins Fontes, 1997.

FLUSSER, Vilém. Filosofia da caixa preta.

Ensaios para uma futura filosofia da fotografia.

Rio de Janeiro: Relume Dumará, 2002.

FLUSSER, Vilém. 0 universo das imagens

técnicas: elogio da superficialidade. São Paulo:

Annablume, 2008.

GATTO, Patrícia Souza. Fotografia e pensamento complexo. 2004. 134 f. Dissertação (Mestrado em Ciências Sociais) - PUCSP, São Paulo, 2004.

GÊNESIS. Português. In: Bíblia Mensagem de
Deus. Coordenação geral das traduções: Pe.

Gabriel C. Galache, S. J. São Paulo: Loyola, 1983.

p. 21-91.

HALL, Stuart. A identidade cultural na pós-

modernidade. Rio de Janeiro: DP\&A, 1999.

HEIDEGGER, Martin. Que é isto, a filosofia?

Identidade e diferença. Petrópolis, RJ: Vozes; São

Paulo: Livraria Duas Cidades, 2006.

MARCONDES, Danilo. Iniciação à história da

filosofia. Rio de Janeiro: Jorge Zahar, 1997.

MARTINI, Gerlaine Torres. A fotografia como

instrumento de pesquisa na obra de Pierre

Fatumbi Verger. 1999. 184 f. Dissertação

(Mestrado em Comunicação) - Universidade de

Brasília, Brasília, 1999.

MARTINS-COSTA, Helena. Através do silêncio.

2006. 84 f. Dissertação (Mestrado em Artes

Plásticas) - Escola de Comunicações e Artes,

Universidade de São Paulo, São Paulo, 2006.

MAUAD, Ana M. 0 olhar engajado: fotografia

contemporânea e as dimensões políticas da

cultura visual. ArtCultura, Uberlândia, v. 10, n.

16, p. 33-50, jan./jun. 2008.

MONTEIR0, Charles. A pesquisa em História e

Fotografia no Brasil: notas bibliográficas. Anos 90,

Porto Alegre, v. 15, n. 28, p.169-185, dez. 2008.

MORAES, Ana Maria Lima de. A construção

de um olhar dentro da fotografia de

documentação: análises de algumas séries 
de Sebastião Salgado. 1999. 142 f. Dissertação

(Mestrado em Multimeios) - Instituto de Artes,

Universidade Estadual de Campinas, Campinas,

1999.

WUNENBURGER, Jean-Jacques. A razão

contraditória - ciências e filosofias modernas: 0

pensamento complexo. Lisboa: Instituto Piaget, 1990. 


\section{Subject and demiurge in the photographic gesture}

\section{Abstract:}

Based on the utterances that give us clues about the creativity and subjectivity in the Brazilian literature on photography, we discuss here the notion of subject presented therein, comparing it against the one deriving from contemporary theories that support the identity's shattering. The conclusion that subjectivism negates creativity because of its binarism has led to turn to Heidegger and Wunenburger for concepts capable of helping us equate the idea of an unstable subject with that of creation. We acknowledge an anthropological obstacle - and not an epistemological one - provided by the constant that at times redounds to schizophreniclike thinking and at others to confused thinking, simultaneously consolidated in the affirmation of arrogant sovereignty over the technique (image) and in the alienated integration to it. We find it is necessary to have a bifurcated solution through the coincidentia oppositorum that makes a third element the support and justification point of what had initially been a binarism, restoring the possible demiurge to the multipliable subject.

\section{Keywords:}

Photography. Subject. Creativity.

\section{Sujeto y demiurgia en el gesto fotográfico}

\section{Resumen:}

A partir de enunciados que dan pistas sobre la creatividad y la subjetividad en la producción teórica brasileña sobre fotografía, se discute la noción de sujeto que ahí se presenta, confrontándola con aquella derivada de las teorías contemporáneas que sustentan el despedazamiento de la identidad. La conclusión de que el subjetivismo niega la creatividad debido a su binarismo lleva a buscarse, junto a Heidegger y a Wunenburger, conceptos que puedan viabilizar el ecuacionamiento de la idea de un sujeto inestable con la de la creación. Se reconoce un obstáculo antropológico -y no epistemológico- ofrecido por la constante que redunda en el pensamiento esquizomorfo o en el pensamiento gliscomórfico, consubstanciado simultáneamente en la afirmación de la soberanía arrogante sobre y en la integración alienada a la (imagen) técnica. Se concluye por la necesidad de una salida bifurcada a través de la coincidentia oppositorum que hace de un tercer elemento el punto de sustentación y justificación de lo que inicialmente fue un binarismo, restituyendo la demiurgia posible al sujeto multiplicable.

\section{Palabras clave:}

Fotografía. Sujeto. Creatividad. 


\section{Expediente}

A revista E-Compós é a publicação científica em formato eletrônico da Associação Nacional dos Programas de Pós-Graduação em Comunicação (Compós). Lançada em 2004, tem como principal finalidade difundir a produção acadêmica de pesquisadores da área de Comunicação, inseridos em instituições do Brasil e do exterior.
E-COMPÓS I www.e-compos.org.br I E-ISSN 1808-2599

Revista da Associação Nacional dos Programas de Pós-Graduação em Comunicação.

Brasília, v.14, n.2, maio/ago. 2011

A identificação das edições, a partir de 2008 passa a ser volume anual com três números.

\section{CONSELHO EDITORIAL}

Afonso Albuquerque, Universidade Federal Fluminense, Brasil Alberto Carlos Augusto Klein, Universidade Estadual de Londrina, Brasil Alex Fernando Teixeira Primo, Universidade Federal do Rio Grande do Sul, Brasil Ana Carolina Damboriarena Escosteguy, Pontifícia Universidade Católica do Rio Grande do Sul, Brasil

Ana Gruszynski, Universidade Federal do Rio Grande do Sul, Brasil Ana Silvia Lopes Davi Médola, Universidade Estadual Paulista, Brasi André Luiz Martins Lemos, Universidade Federal da Bahia, Brasil Ângela Freire Prysthon, Universidade Federal de Pernambuco, Brasil Angela Cristina Salgueiro Marques, Faculdade Cásper Líbero (São Paulo), Brasil Antônio Fausto Neto, Universidade do Vale do Rio dos Sinos, Brasil Antonio Carlos Hohlfeldt, Pontifícia Universidade Católica do Rio Grande do Sul, Brasil Antonio Roberto Chiachiri Filho, Faculdade Cásper Libero, Brasil Arlindo Ribeiro Machado, Universidade de São Paulo, Brasil Arthur Autran Franco de Sá Neto, Universidade Federal de São Carlos, Brasil Benjamim Picado, Universidade Federal Fluminense, Brasil César Geraldo Guimarães, Universidade Federal de Minas Gerais, Brasil Cristiane Freitas Guttreind, Pontifícia Universidade Católica do Rio Grande do Sul, Brasi Denilson Lopes, Universidade Federal do Rio de Janeiro, Brasil Denize Correa Araujo, Universidade Tuiuti do Paraná, Brasil Edilson Cazeloto, Universidade Paulista , Brasil Eduardo Peñuela Cañizal, Universidade Paulista, Brasi Eduardo Vicente, Universidade de São Paulo, Brasi Eneus Trindade, Universidade de São Paulo, Brasil Erick Felinto de Oliveira, Universidade do Estado do Rio de Janeiro, Brasil Florence Dravet, Universidade Católica de Brasília, Brasil Francisco Eduardo Menezes Martins, Universidade Tuiuti do Paraná, Brasi Gelson Santana, Universidade Anhembi/Morumbi, Brasil Gilson Vieira Monteiro, Universidade Federal do Amazonas, Brasi Gislene da Silva, Universidade Federal de Santa Catarina, Brasil Guillermo Orozco Gómez, Universidad de Guadalajara Gustavo Daudt Fischer, Universidade do Vale do Rio dos Sinos, Brasil Hector Ospina, Universidad de Manizales, Colômbia Herom Vargas, Universidade Municipal de São Caetano do Sul, Brasil leda Tucherman, Universidade Federal do Rio de Janeiro, Brasil Inês Vitorino, Universidade Federal do Ceará, Brasi Janice Caiafa, Universidade Federal do Rio de Janeiro, Brasil Jay David Bolter, Georgia Institute of Technology Jeder Silveira Janotti Junior, Universidade Federal de Pernambuco, Brasil João Freire Filho, Universidade Federal do Rio de Janeiro, Brasi
John DH Downing, University of Texas at Austin, Estados Unidos José Afonso da Silva Junior, Universidade Federal de Pernambuco, Brasil José Carlos Rodrigues, Pontifícia Universidade Católica do Rio de Janeiro, Brasil José Luiz Aidar Prado, Pontifícia Universidade Católica de São Paulo, Brasil José Luiz Warren Jardim Gomes Braga, Universidade do Vale do Rio dos Sinos, Brasil Juremir Machado da Silva, Pontifícia Universidade Católica do Rio Grande do Sul, Brasil Laan Mendes Barros, Universidade Metodista de São Paulo, Brasil Lance Strate, Fordham University, USA, Estados Unidos Lorraine Leu, University of Bristol, Grã-Bretanha Lucia Leão, Pontifícia Universidade Católica de São Paulo, Brasil Luciana Panke, Universidade Federal do Paraná, Brasil Luiz Claudio Martino, Universidade de Brasilia, Brasil Malena Segura Contrera, Universidade Paulista, Brasil Márcio de Vasconcellos Serelle, Pontifícia Universidade Católica de Minas Gerais, Brasil Maria Aparecida Baccega, Universidade de São Paulo e Escola Superior de Propaganda e Marketing, Brasil

Maria das Graças Pinto Coelho, Universidade Federal do Rio Grande do Norte, Brasil Maria Immacolata Vassallo de Lopes, Universidade de São Paulo, Brasil Maria Luiza Martins de Mendonça, Universidade Federal de Goiás, Brasil Mauro de Souza Ventura, Universidade Estadual Paulista, Brasil Mauro Pereira Porto, Tulane University, Estados Unidos Nilda Aparecida Jacks, Universidade Federal do Rio Grande do Sul, Brasi Paulo Roberto Gibaldi Vaz, Universidade Federal do Rio de Janeiro, Brasi Potiguara Mendes Silveira Jr, Universidade Federal de Juiz de Fora, Brasil Renato Cordeiro Gomes, Pontifícia Universidade Católica do Rio de Janeiro, Brasil Robert K Logan, University of Toronto, Canadá

Ronaldo George Helal, Universidade do Estado do Rio de Janeiro, Brasil Rosana de Lima Soares, Universidade de São Paulo, Brasil Rose Melo Rocha, Escola Superior de Propaganda e Marketing, Brasil Rossana Reguillo, Instituto de Estudos Superiores do Ocidente, Mexico Rousiley Celi Moreira Maia, Universidade Federal de Minas Gerais, Brasil Sebastião Carlos de Morais Squirra, Universidade Metodista de São Paulo, Brasi Sebastião Guilherme Albano da Costa, Universidade Federal do Rio Grande do Norte, Brasil

Simone Maria Andrade Pereira de Sá, Universidade Federal Fluminense, Brasil Tiago Quiroga Fausto Neto, Universidade de Brasília, Brasi Suzete Venturelli, Universidade de Brasília, Brasil Valério Cruz Brittos, Universidade do Vale do Rio dos Sinos, Brasil Valerio Fuenzalida Fernández, Puc-Chile, Chile Veneza Mayora Ronsini, Universidade Federal de Santa Maria, Brasil Vera Regina Veiga França, Universidade Federal de Minas Gerais, Brasil

\section{COMISSÃO EDITORIAL}

Adriana Braga I Pontifícia Universidade Católica do Rio de Janeiro, Brasil Felipe Costa Trotta I Universidade Federal de Pernambuco, Brasil

CONSULTORES AD HOC

Bárbara Heller, Universidade Paulista, Brasil

Luciana Mielniczuk, Universidade Federal do Rio Grande do Sul, Brasil Micael Herschmann, Universidade Federal do Rio de Janeiro, Brasil EDIČ̃̃ DE TEXTO E RESUMOS I Susane Barros SECRETÁRIA EXECUTIVA I Juliana Depiné EDITORAÇ̃o ELETRÔNICA I Roka Estúdio TRADUÇÃO I Sabrina Gledhill, Sieni Campos, Robert Finnegan
COMPós I www.compos.org.br

Associação Nacional dos Programas de Pós-Graduação em Comunicação

Presidente

Julio Pinto

Pontifícia Universidade Católica de Minas Gerais, Brasi

juliopinto@pucminas.br

Vice-presidente

Itania Maria Mota Gomes

Universidade Federal da Bahia, Brasi

itania@ufba.br

Secretária-Gera

Inês Vitorino

Universidade Federal do Ceará, Brasil

inesvict@gmail.com 